\title{
Heterocyclization Reactions of Pyruvic Acids and Aminoazoles with Controlled Chemoselectivity
}

\author{
Yana I. Sakhno, ${ }^{\text {a }}$ Maryna V. Murlykina, ${ }^{a}$ Alisa D. Morozova, ${ }^{a}$ Anton V. Kozyryev,,${ }^{a, b}$ \\ and Valentin A. Chebanov*a,b \\ a State Scientific Institution "Institute for Single Crystals” NAS of Ukraine, Lenin Ave. 60, 61178, \\ Kharkiv, Ukraine \\ ${ }^{\mathrm{b}}$ V.N. Karazin Kharkiv National University, Svobody sq. 4, UA-61022, Kharkiv, Ukraine \\ chebanov@isc.kharkov.com
}

Keywords: heterocyclization reaction, pyruvic acid, aminoazole, chemoselectivity, diversity oriented synthesis.

The present review includes the analysis of known literature data concerning linear and multicomponent heterocyclizations involving pyruvic acids and aminoazoles. In particular, the review demonstrates the approaches to control regio- and chemoselectivity of these types of treatments and their application to solve the matters of Diversity Oriented Synthesis.

\section{Introduction}

The significance of pyruvic acid in our life can be hardly overestimated. It plays a vital role as one of the most reactive substances among those of important in cellular metabolism. That is why a conclusion may be made that reactions involving pyruvic acid may help to solve some health problems and assist in finding a cure against various diseases today and in future. Heterocyclization reactions of pyruvic acids with nitrogen containing nucleophiles play an important role in the synthesis of heterocyclic compounds having diverse types of physiological activities such as antimalarial [1, 2], antitumor [3], antimicrobial [4], antifungal [5] and analgesic [6-8] activities. Thus, study of chemical behavior of pyruvic acid and its derivatives in chemical reactions are interesting from several points of view.

The first multicomponent reaction involving pyruvic acid was discovered in the late $19^{\text {th }}$ century $[9,10]$ by Doebner - the threecomponent condensation of pyruvic acid, aldehydes and aniline derivatives leading either to quinoline carboxylic acids or to pyrrolidine-2,3diones (Scheme 1). Further this reaction was studied in details in numerous publications [3, 11-22].

Initially, it had been considered that the Doebner reaction proceeded via formation of arylidenepyruvic acid [11], however, later that way was refuted and an alternative mechanistic 
pathway involving the formation of a Schiff base followed by cyclization was proposed [15, $18,19]$.
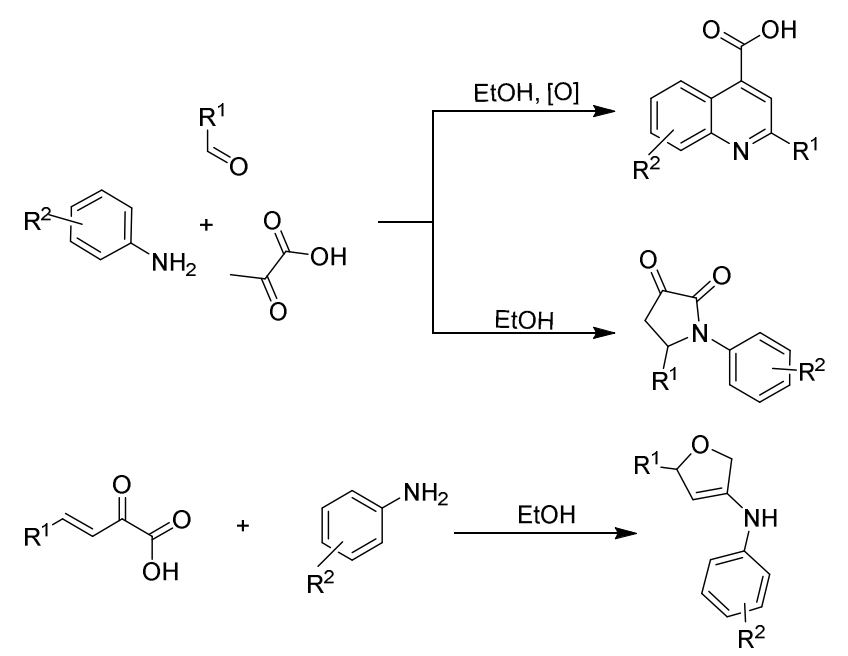

Scheme 1.

On the other hand, reaction of arylidenepyruvic acids and aromatic amines led to 3arylamino-5-aryl-2(5H)furanones [20] but not to pyrrolidine-2,3-diones as it had been reported earlier (Scheme 1) [21]. It should be noted that different procedures for Doebner reaction were developed [23-27] based on the variation of solvents, catalysts and activation methods.

The Doebner-like multicomponent reactions of phenylpyruvic acid with aromatic aldehydes and aromatic amines, also yielded either pyrrolidine-2,3-dione or quinoline-4-carboxylic acid depending on substituents $R^{1}$ and $R^{2}$ (Scheme 2) [12].

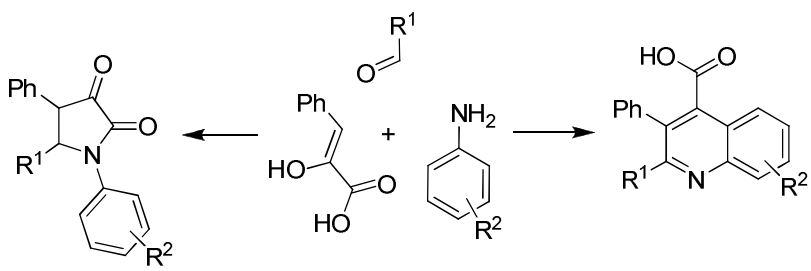

Scheme 2.
However, in this case no clear relationship between the electronic character of the substituents and structure of the reaction products was established.

An interesting approach to the synthesis of quinoxaline derivatives via Ugi-type reaction was proposed as well (Scheme 3) [28]. Thus, the four-component reaction of the starting reagents in $\mathrm{MeOH}$ yielded the Ugi adducts, which by means of acid catalysis turned into quinoxalinones.

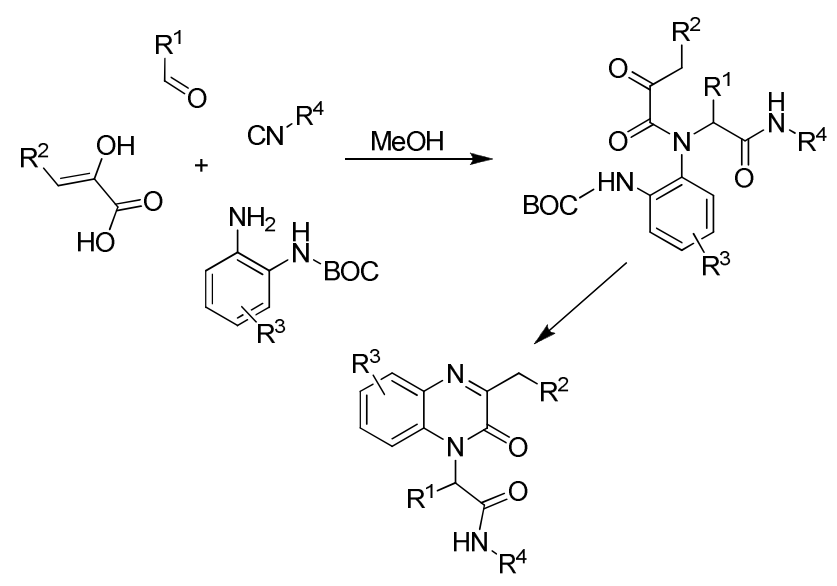

Scheme 3.

Such type of Ugi reaction allowed to synthesize a wide range of quinoxaline derivatives having different types of biological activities: among them inhibitors of various enzymes, as well as benzodiazepine receptor agonists were found [28].

Some publications deal with arylpyruvic acids as $\alpha$-ketoacids and describe their transformations with 1,2-diamines also yielding quinoxalines or analogous heterocyclic systems. [29-32]

In publication [33] it was shown that Biginelli-like condensation of arylpyruvic acids 
with aromatic aldehydes and urea in the presence of catalytic amounts of acid yielded dihydropyrimidine carboxylic acids (Scheme 4). Similar pyrimidines were synthesized by using a polymer-supported solid-phase procedure [34].<smiles>[R]C=COC(O)C(=O)O</smiles>

Scheme 4.

There are a lot of papers about already known and currently studied biological activity of azoloazine structures, e.g. antifungal [35] and antimicrobial [35, 36], hypoglycemic activity [37], in particular, (DPP4) inhibition [38], cardiovascular activity [39], etc. However, multicomponent procedures involving pyruvic acid or its derivatives, aromatic aldehydes, and heterocyclic amines, for example aminoazoles, have been previously rarely investigated. Aside from our publications which are discussed in the General part of the review, recently, we have found some publications in the literature devoted to the reactions involving pyruvic acid and its derivatives with aminoazoles. Li-Yan Zeng and coworkers reported one-pot treatment of pyruvic acid with 5-aminotetrazole and structurally diverse aryl aldehydes which gave 5-aryl5,8-dihydrotetrazolo[1,5-a]pyrimidine-7carboxylic acids (Scheme 5) [40, 41].

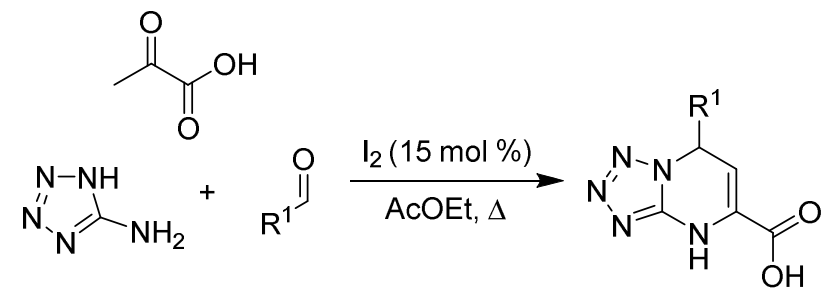

Scheme 5.

In publication [42] it was considered that multicomponent reaction involving pyruvic acid and 5-amino-1-phenyl-3-(pyridine-3-yl)- $1 H$ pyrazole with aromatic aldehydes in boiling acetic acid gave 4-substituted-1-phenyl-3(pyridin-3-yl)-1H-pyrazolo[3,4-b]pyridine-6carboxylic acids in $54-75 \%$ yields (Scheme 6). The reactions were carried out by two different techniques - by conventional heating and under microwave irradiation. The compounds obtained were screened for their antibacterial and antitumor activities with positive results.

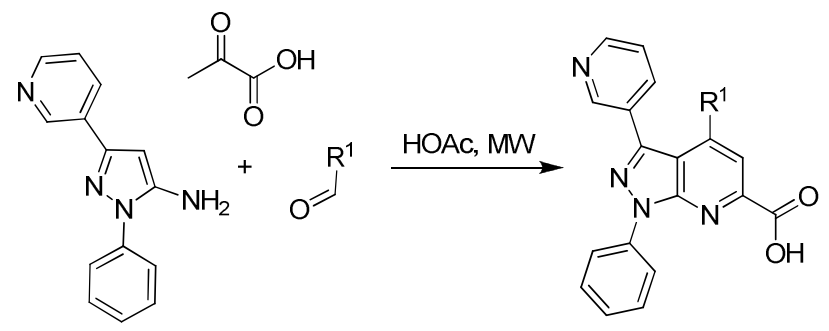

Scheme 6.

It should be noted, that multicomponent cyclization of 5-amino-3-methyl-1-phenyl-1Hpyrazole with aromatic aldehydes and ethyl pyruvate led to the formation of a different set of pyrazolo[3,4- $b]$ pyridine-4-carboxylates as reaction product [43] (Scheme 7), instead of pyrazolopyridines described above [42]. 


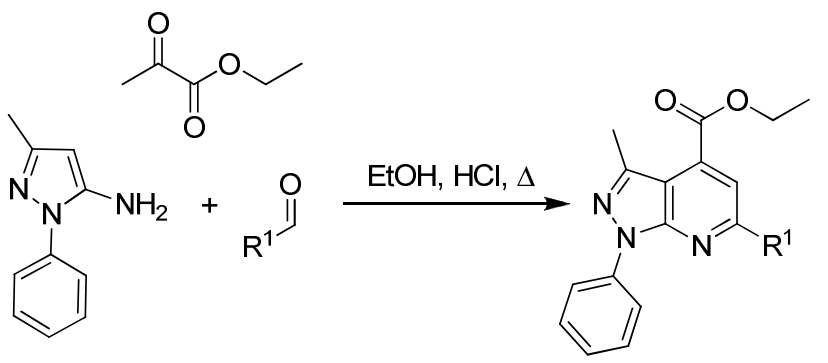

Scheme 7.

In vitro biological evaluation of pyrazole[3,4- $b]$ pyridine derivatives, as a new antichagasic agent series, were carried out [43].

\section{General part}

One of the first reactions [44] involving pyruvic acids and aminoazoles was twocomponent condensation (Scheme 8). The preliminary treatment of pyruvic acid (1) and aldehydes $\mathbf{2}$ gave the starting arylidenepyruvic acids 3 which further reacted with 5-aminotetrazole (4) upon heating in DMF leading to dihydrotetrazolopyrimidine carboxylic acids 5 (Scheme 8).
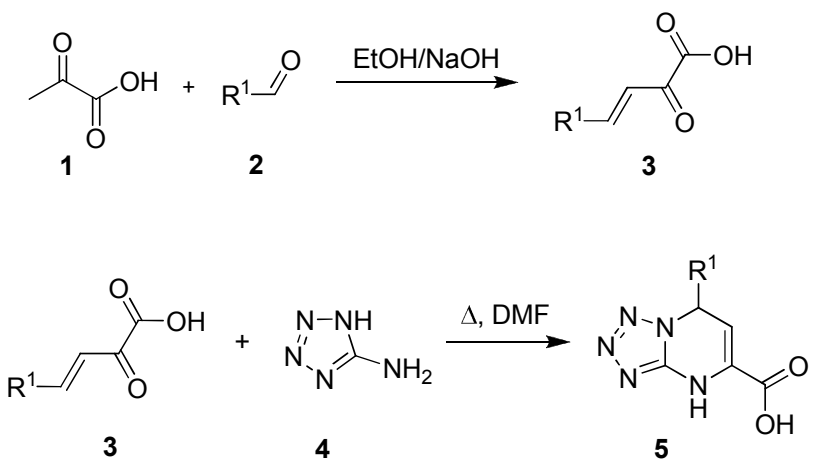

2, 3: $\mathrm{R}^{1}=\mathrm{C}_{6} \mathrm{H}_{5}, 4-\mathrm{CH}_{3} \mathrm{OC}_{6} \mathrm{H}_{4}, 4-\mathrm{ClC}_{6} \mathrm{H}_{4}, 4-\mathrm{FC}_{6} \mathrm{H}_{4}$

\section{Scheme 8.}

Afterwards the potential biological activity of the compounds 5 was studied with the help of computational analysis using the system
PASS-C\&T 4.00. The results of the screening showed that dihydrotetrazolopyrimidines $\mathbf{5}$ might possess cardiovascular, anticonvulsant, cardioprotector and fibrinolytic types of activity.

However, the authors [45] mentioned about one significant drawback in the described reaction. The first stage of that procedure gave arylidenpyruvic acids 3 in very low yields (15$30 \%$ ) while the second stage yields were within $40-60 \%$ range and the general efficiency of this two-staged reaction was unsatisfactory. Thereby, the next publications were dedicated to the applying multicomponent reactions as an alternative pathway for the synthesis of azolopyrimidine carboxylic acid derivatives from appropriate aminoazoles, aromatic aldehydes and pyruvic acids.

Refluxing 5-aminotetrazole (4), aromatic aldehydes 2 and pyruvic acid (1) in DMF or glacial acetic acid led to the formation of the same fused dihydropyrimidines 5 (Scheme 9) that allowed to save time, reagents and to enhance the yields [45].

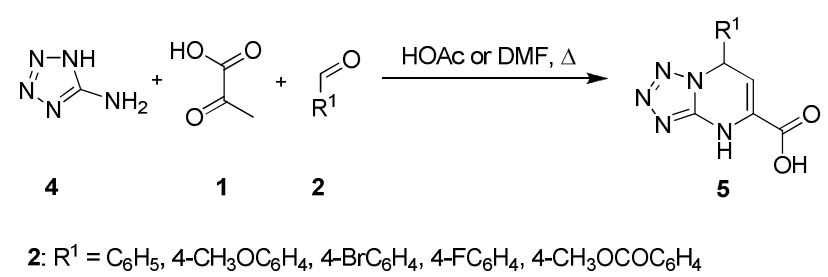

Scheme 9.

Nowadays there is a wide set of approaches for controlling the selectivity of multicomponent reactions such as classical ones like variation of the parameters of the reaction me- 
dium (e.g. the solvent and catalyst types, time regime etc.) and non-classical methods like microwave and ultrasonic irradiation, etc. Moreover, modification of the structures of the starting reagents, thereby increasing their polyfunctionality, may also considerably influence the reaction proceeding and cause the formation of different types of final heterocycles [46-51].

In the publications $[45,52,53]$ an influence of substituents in the aldehyde and pyruvic acid components on a proceeding their heterocyclizations with 3-amino-1,2,4-triazole derivatives was studied. Particularly, variation of the temperature regime together with applying nonclassical activation methods (ultrasonic and microwave irradiation) allowed to switch the reaction between several directions and to obtain selectively several chemotypes of final structures.

Thus, the behavior of 3-amino-1,2,4triazole (6) in the three-component condensation with aromatic aldehydes $\mathbf{2}$ and pyruvic acid (1) turned up to be quite the same to the 5aminotetrazole (4) reactivity [45]. Refluxing 3amino-1,2,4-triazole (6) and aromatic aldehydes $\mathbf{2}$ with pyruvic acid (1) in glacial acetic acid allowed to isolate from the reaction mixtures the pure acids 8 with good yields (Pathway B, Scheme 10). At the same time, heating the starting compounds 1, 2 and $\mathbf{6}$ in DMF led to mixtures of two regioisomeric dihydrotriazolopyrimidines 8 and 9 (Pathway D, Scheme 10). All attempts to separate these mixtures by crystalli- zation or using HPLC were unsuccessful [45, 53].

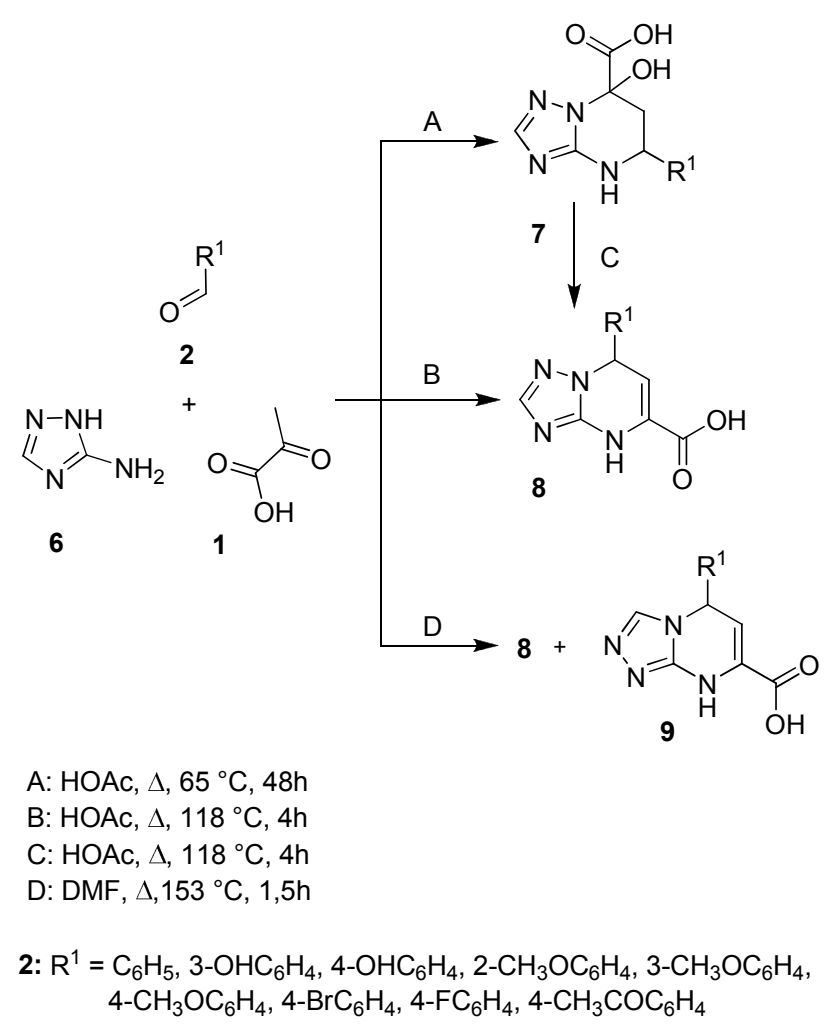

Scheme 10.

Over time, Murlykina et al. [53] discovered that decreasing the temperature up to $65^{\circ} \mathrm{C}$ in the reaction of the same starting materials $\mathbf{1}$, 2 and 6 led to the formation of tetrahydropyrimidines 7 (Pathway A, Scheme 10). It should be noted that boiling the compounds 7 in acetic acid for 4 hours via decomposition / heterocyclization / dehydratation sequence [45] also led to the formation of heterocycles 8 (Pathway C, Scheme 10).

On the contrary, heating the compounds 11, derived from 2-hydroxybenzaldehyde 10, in HOAc led to the tarring of the reaction mixture, and no individual product was isolated. However, their MW irradiating in $\mathrm{MeOH}\left(140{ }^{\circ} \mathrm{C}, 50\right.$ min) finally allowed to get dihydropyrimidines 
12 (Scheme 11). Decreasing the reaction temperature up to $130{ }^{\circ} \mathrm{C}$ yielded the mixture of two regioisomeric compounds 12 and 13 [53]. The authors [53] varied the temperature, solvents and different catalysts, however, neither an in- creasing the yield of $\mathbf{1 2}$ nor a selective isolation of compounds $\mathbf{1 3}$ was achieved. All attempts to obtain dihydropyrimidines $\mathbf{1 2}$ or $\mathbf{1 3}$ in the threecomponent condensation were also unsuccessful.

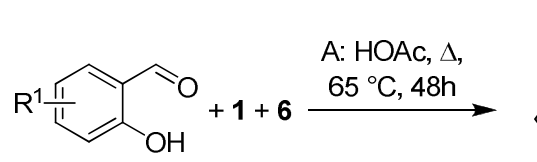

10

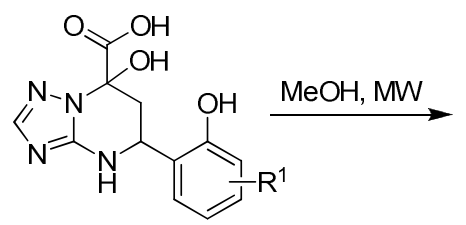

11

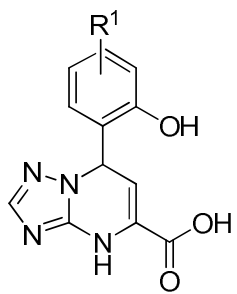

12

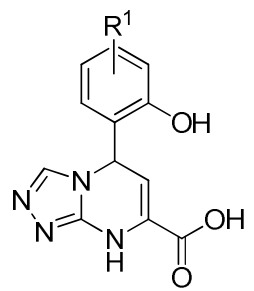

13 10: $\mathrm{R}^{1}=\mathrm{H} ; 3-\mathrm{CH}_{3} \mathrm{O}$

Scheme 11.

As it was mentioned before multicomfor 180 minutes provided pyrrolones $\mathbf{1 7}$. Reacponent reactions involving arylpyruvic acids and aminoazoles leading to heterocyclic compounds have been rarely investigated, thereby, it was interesting to disclose an influence of an introduction of a $\beta$-aryl substituent into pyruvic acid on the reaction proceeding. Thus, the authors $[52,53]$ disclosed the results on the tuning multicomponent condensation reactions of 5aminotetrazole (4) or 3-amino-1,2,4-triazole derivatives 6 and $\mathbf{1 4}$ with aldehydes and arylpyruvic acids using both traditional and nonclassical activation methods. It was found that the condensation of aminotriazoles 6, 14 with arylpyruvic acids $\mathbf{1 5}$ and aromatic aldehydes $\mathbf{2}$ in boiling acetic acid led to different products depending on the reaction conditions. Particularly, tetrahydrotriazolopyrimidine carboxylic acids $\mathbf{1 6}$ were isolated after refluxing equimolar amounts of the starting materials 2, $\mathbf{1 5}$ and $\mathbf{6}$ or $\mathbf{1 4}$ in acetic acid for 2-3 minutes while reaction tion times within those extremes in most cases led to the formation of both heterocycles $\mathbf{1 6}$ and 17 (Scheme 12).

The experimental data obtained [52] indicated that in this three-component condensation (Scheme 12) the fused pyrimidines 16 were the kinetically controlled reaction products while pyrrolones $\mathbf{1 7}$ might be considered as the thermodynamically controlled products. In addition, the authors applied ultrasonic and microwave irradiation: treatment the starting materials 2, 15 and 6 or $\mathbf{1 4}$ for $c a .30$ minutes under ultrasonication yielded exclusively fused triazolopyrimidinecarboxylic acids $\mathbf{1 6}$ and these conditions were chosen as the optimal ones; on the other hand, MW irradiating the mixture of the same starting materials in acetic acid at $170{ }^{\circ} \mathrm{C}$ allowed to obtain pyrrolones 17 with almost 9fold time reduction as compared with the thermal heating $[52,53]$. 


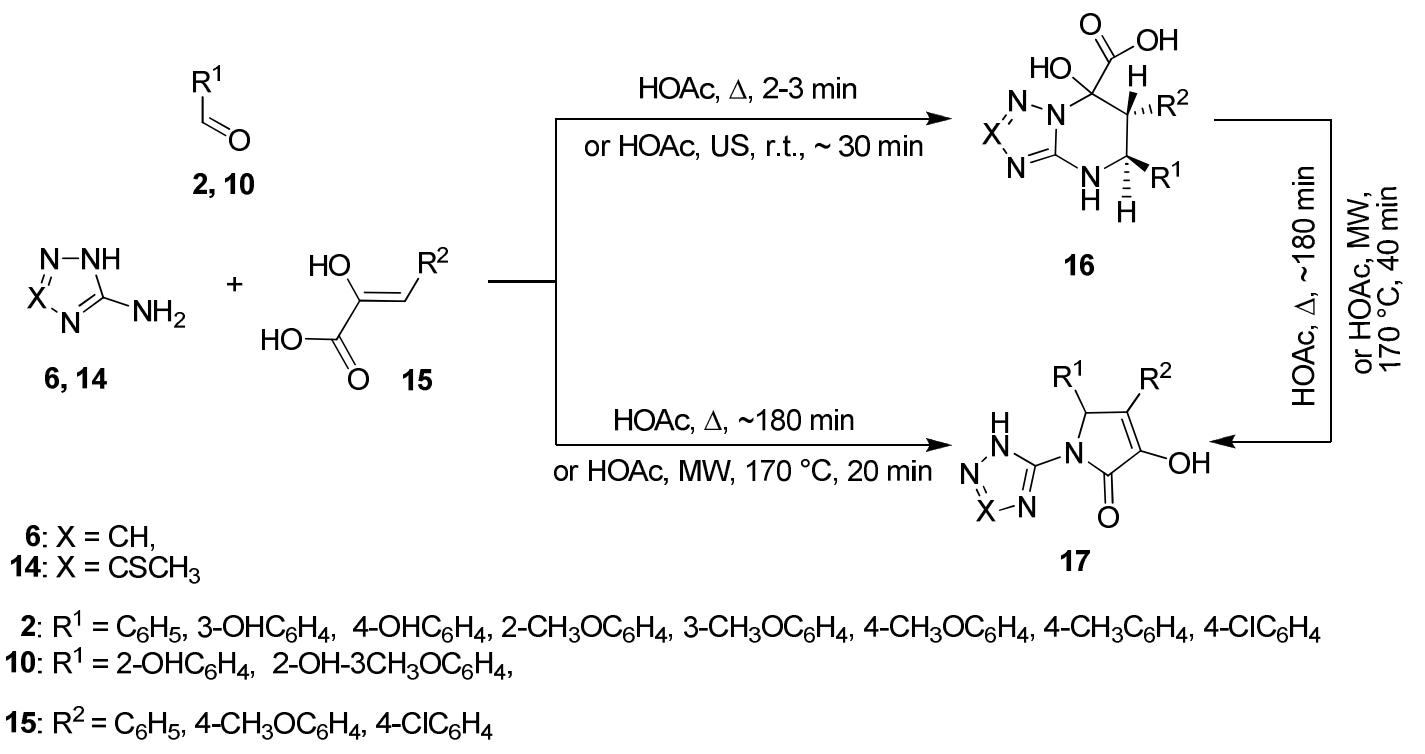

Scheme 12.

Afterwards the studies of antibacterial The reference compound amantadine had an and antiviral activities of the compounds syn$\mathrm{IC}_{50}$ of $13.5 \mu \mathrm{M}$, demonstrating that compound thesized were carried out in vitro [53]. The tested substances didn't show high antibacterial activity, however, for several of them sufficient 17 was at least 20 -fold more active than the reference drug.

Multicomponent condensations involvincrease in biomass of test-cultures compared ing 5-aminotetrazole (4) in boiling acetic acid with control was found. The promising result (or with applying MW irradiation) provided the was also obtained for pyrrolone $17\left(\mathrm{R}^{1}=2\right.$ - formation of only pyrrolones 18 being analo$\mathrm{CH}_{3} \mathrm{OC}_{6} \mathrm{H}_{4}$ ). This compound showed high activity against influenza $\mathrm{A} / \mathrm{H} 1 \mathrm{~N} 1$ with an average $\mathrm{IC}_{50}$ value of $0.57 \mu \mathrm{M}$ and a $\mathrm{CC}_{50}>100 \mu \mathrm{M}$. (Scheme 13).

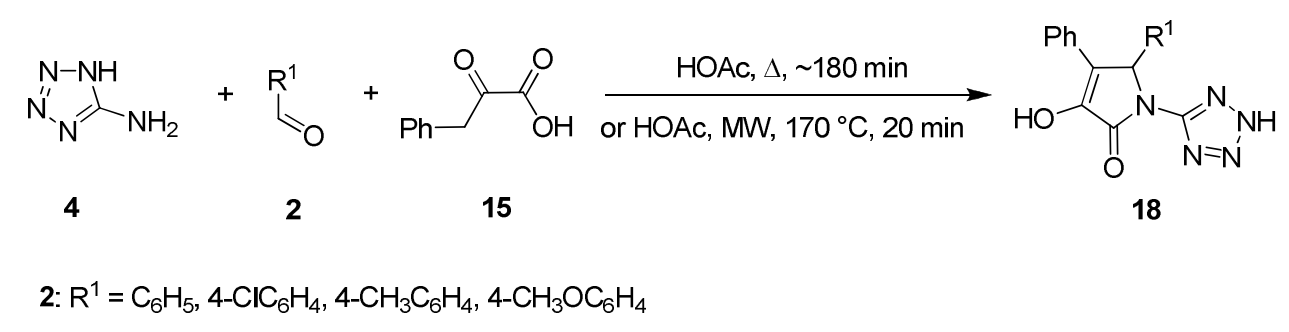

Scheme 13.

This fact was explained by Sakhno et al. [52] regarding the mechanistic aspects of these via the initial formation of azomethines $\mathbf{1 9}$ and their subsequent reaction with arylpyruvic acids reactions (Scheme 14). Thus, the three15 which was not a synchronous process component reaction of the starting materials $\mathbf{2}$, $\mathbf{1 5}$ and 6 or $\mathbf{1 4}$ at room temperature giving tria(pathway "a", Scheme 14). The authors [52] zolopyrimidines $\mathbf{1 6}$ most probably proceeded ment of preliminary synthesized Schiff base 19 
with arylpyruvic acids 15 yielding triazolopyrimidines $\mathbf{1 6}$ and by observation of compounds of type $\mathbf{1 9}$ in trace amounts in the mother liquor of the multicomponent reaction.

According to the hypothesis [52] 5aminotetrazole (4) formed no azomethine with aldehydes and, therefore, the appropriate tetrazolopyrimidines were not isolated.

The pathway of high-temperature reaction leading to pyrrolones $\mathbf{1 7}$ and $\mathbf{1 8}$ is also unusual and its mechanism seems unclear. In this condensation aminoazoles 4, 6, 14 act as mononucleophiles like anilines $[54,55]$. Described in the literature [56] related three-component reaction of anilines, pyruvic acids and aldehydes proceeds through the formation of furanone derivatives like 20 (pathway "b", Scheme 14).

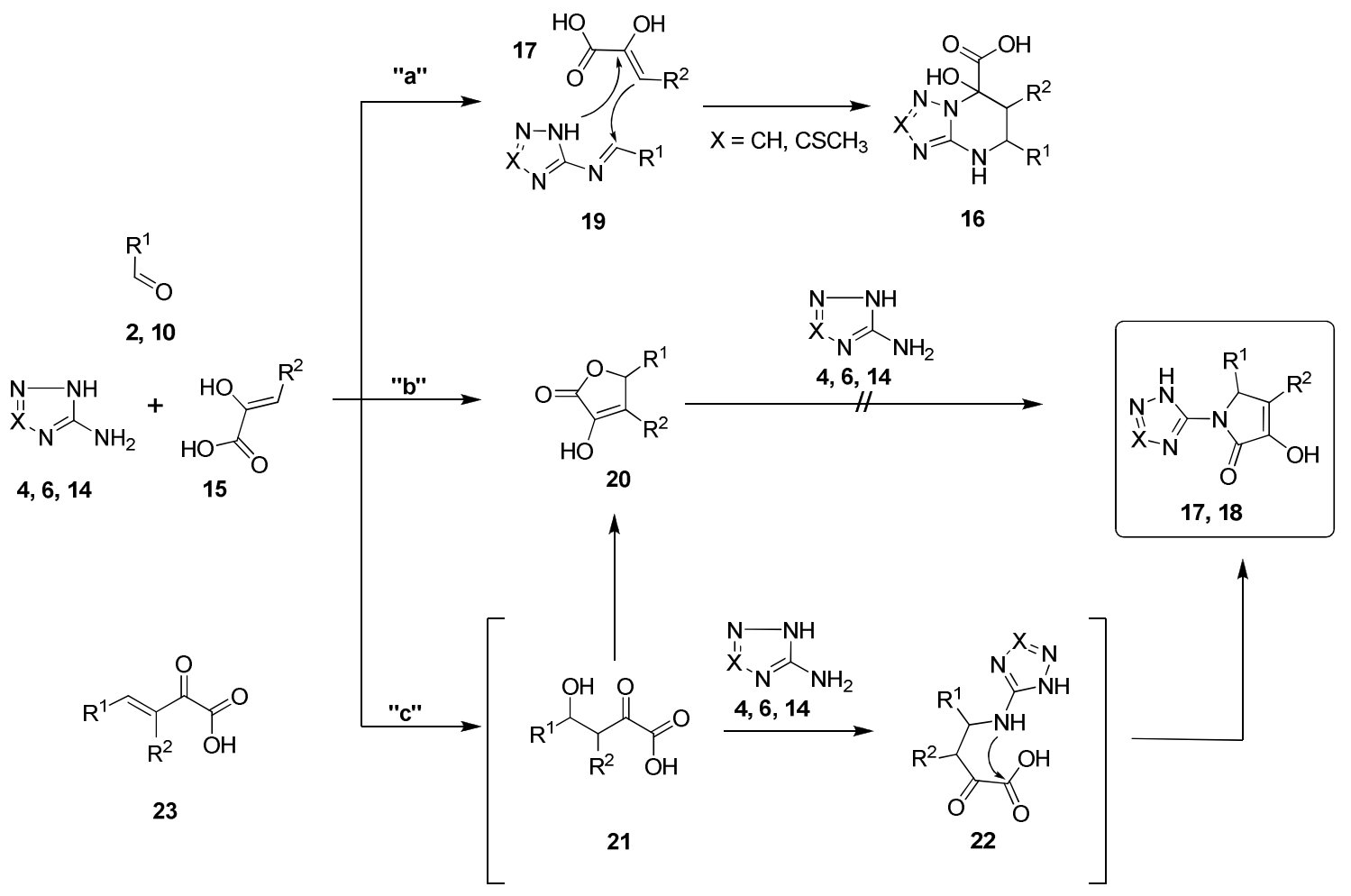

However, it was established that compounds $\mathbf{2 0}$, synthesized by reaction of arylpyruvic acids and aldehydes [57], did not react with aminoazoles 4, 6, 14 and, therefore, could not be intermediates in that multicomponent process.

The authors [52] proposed the probable sequence that might include formation of aldols 21 at the first stage of the high-temperature three-component reaction, subsequent nucleophilic substitution of the hydroxyl group with aminoazole (intermediate 22) and, ultimately, an intramolecular condensation (pathway "c", Scheme 14). The other mechanisms cannot be also excluded, e.g., via arylidenephenylpyruvic acids $\mathbf{2 3}$ formed by water elimination from aldols 21.

Scheme 14 
However, Sakhno et al. [52] didn't succeed in the attempts to synthesize the compounds 23 by the direct reaction of arylpyruvic acids $\mathbf{1 5}$ and aldehydes $\mathbf{2}$ under different condition which was in good agreement with the literature data for the synthesis of similar unsaturated acids [58].

Based on the results obtained revealing several rules in the proceeding condensations of aminoazoles and arylidenepyruvic acids (or their synthetic precursors) the influence of the modifying aminoazole on the reaction behavior was studied as well. Among the polyfunctional aminoazoles, applied in the heterocyclizations with carbonyl compounds, 3,5-diamino-1,2,4triazole is of an interest due to the presence of several alternative reaction centers which usually results in formation of pyrimidine structures with additional possibility of further modification of the cyclization products. Moreover, introduction of an aryl substituent at position 1 of the diaminotriazole gives rise to specific properties that have been studied in details by Chernyshev et al. [59-63], Papini et al. [64-66] and other authors [67].

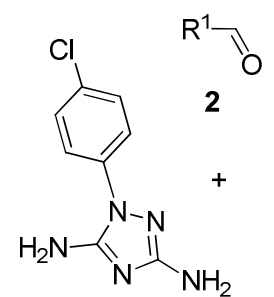

24

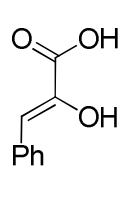

15

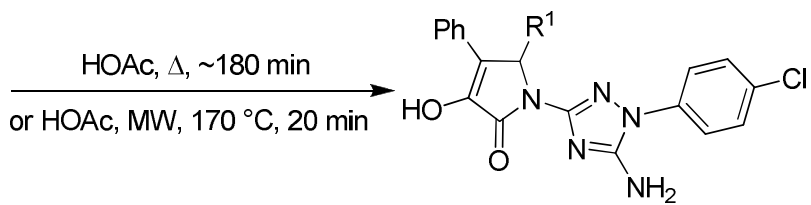

25

2: $\mathrm{R}^{1}=\mathrm{C}_{6} \mathrm{H}_{5}, 4-\mathrm{CIC}_{6} \mathrm{H}_{4}, 4-\mathrm{CH}_{3} \mathrm{C}_{6} \mathrm{H}_{4}, 4-\mathrm{CH}_{3} \mathrm{OC}_{6} \mathrm{H}_{4}$

Scheme 15.

However, 1-(4-clorophenyl)-3,5diamino-1,2,4-triazole (24) in the reaction with phenylpyruvic acid (15) and aromatic aldehydes $\mathbf{2}$ showed the similar to aminotetrazole $\mathbf{4}$ behavior: after the heating or MW irradiating the starting materials (Scheme 15) in acetic acid corresponding pyrrolones $\mathbf{2 5}$ were synthesized while all the attempts to isolate tetrahydropyrimidines like 16 (Scheme 12) were unsuccessful [52].

The analogous multicomponent condensation involving unsubstituted pyruvic acid (1) proceeded in an unusual direction. It was established [68] that three-component treatment of diaminotriazole 24, aromatic aldehydes $\mathbf{2}$ and pyruvic acid (1) in boiling DMF gave unexpected 3-[5-amino-1-(4-chlorophenyl)- $1 \mathrm{H}$ 1,2,4-triazol-3-ylamino]-5-arylfuran-2-ones $\mathbf{2 6}$ (Method A, Scheme 16). The authors [68] emphasize that neither triazolopyrimidines like $\mathbf{1 6}$ (Scheme 12) nor pyrrolone derivatives of type 25 (Scheme 15) were isolated or even chromatographically detected in the mother liquor.

The direction of the sequential reaction (Scheme 16, method B) via preliminary synthesis of arylidenepyruvic acids $\mathbf{3}$ was identical to the multicomponent procedure. 

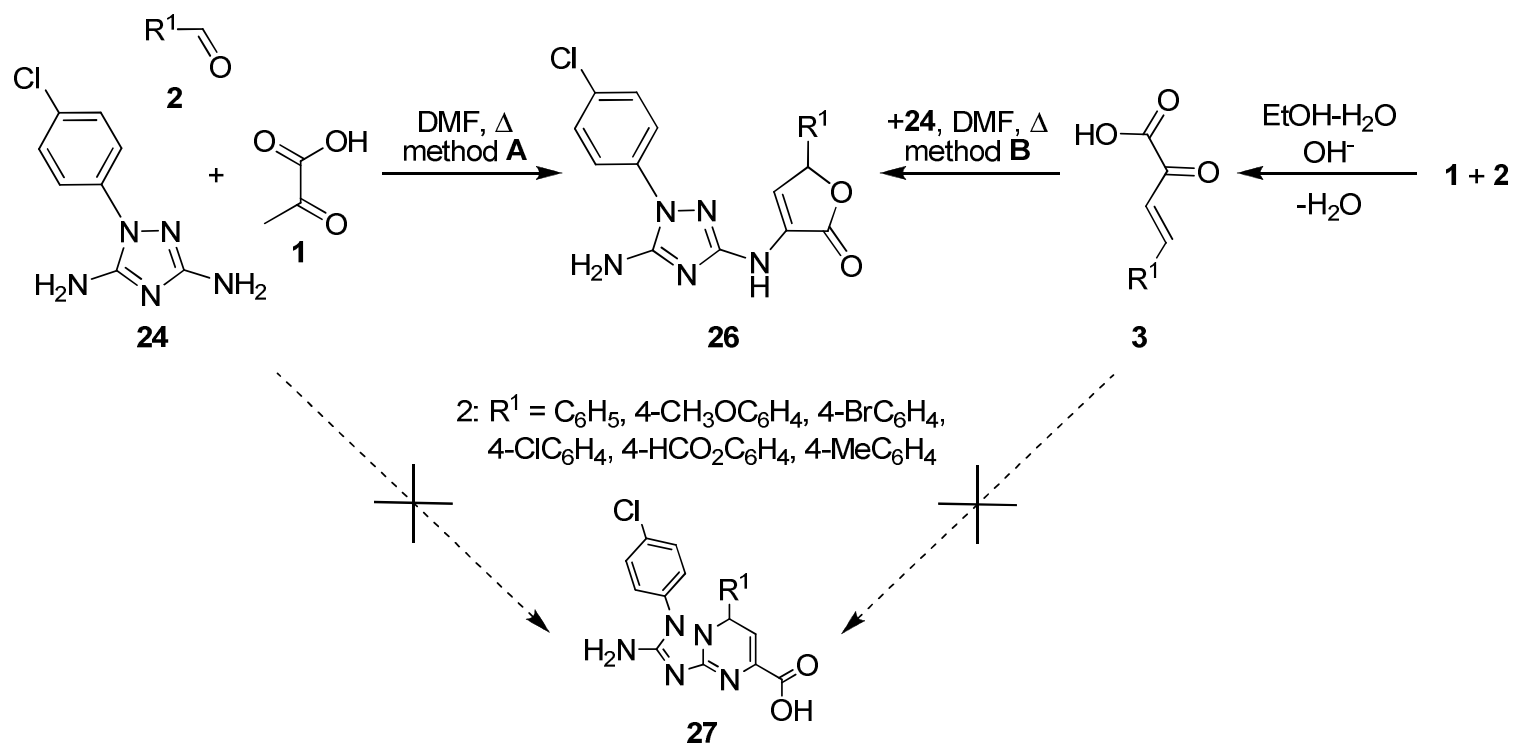

Scheme 16.

It was found that refluxing diaminotriazole 24 and unsaturated acids 3 in DMF led to the formation of the same triazolofuranones $\mathbf{2 6}$, however the yields were smaller [68].

An alternative direction leading to triazolopyrimidines 27 was disfavored owing to the fact of a loss of aromaticity by the aminoazole moiety during the reaction (Scheme 16).

The most probable way for the formation of triazolylfuranones $\mathbf{2 6}$ was suggested in publication [68] and included the attack of one of the $\mathrm{NH}_{2}$ groups of diaminotriazole 24 on the $\beta$ carbonyl group of pyruvic acid (1) with formation of azometines $\mathbf{2 8}$ followed by the cyclization with an aldehyde component $\mathbf{2}$ into the corresponding furanones 26 (Scheme 17). Formation of imines like $\mathbf{2 8}$ in analogues heterocyclizations involving aromatic or heterocyclic amines and pyruvic acids was previously described and discussed in several works [69-73]. According to the authors [68], other possible pathways, e.g., via preliminary in situ formation of arylidenepyruvic acids $\mathbf{3}$ or even whole furanone moiety were doubtful because of the previous negative results obtained for analogues multicomponent reactions (Scheme 14) [45, $52]$.

On the other hand, the fact of isolation of triazolylpyrrolones $\mathbf{2 5}$ in the reaction involving phenylpyruvic acid (15) [52] (Scheme 15) can be explained by the specific influence of the phenyl substituent preventing the formation of the intermediate like 29.

Similarly, the mechanism of the sequential reaction (Scheme 17) leading to the furanones 26 can take place via formation of imines 29 and their further cyclization into the final compounds $\mathbf{2 6}$.

Reactions of 5-aminopyrazoles with pyruvic acids can also proceed in several directions and lead to fused pyridine or pyrimidine carboxylic acids; therefore, they are interesting from the point of view of chemo- and regioselectivity. In addition, high interest in the study 
of pyridine and pyrimidine heterocycles containing fused pyrazole rings is mainly caused by the known biological activity of these systems reported in the literature [74-77].
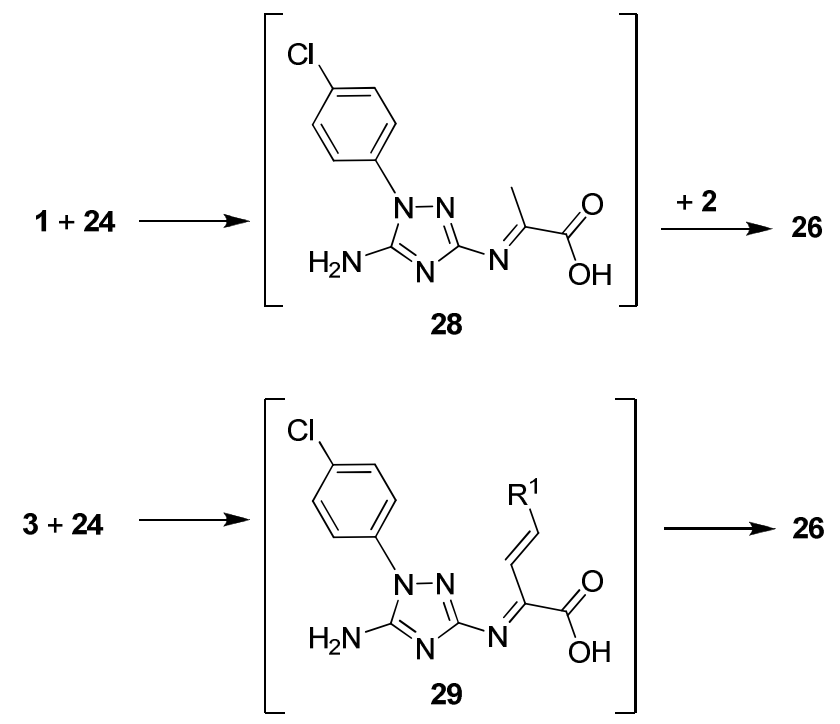

Scheme 17.

The article [78] described the treatment of arylidenepyruvic acids or pyruvic acids with aromatic aldehydes and substituted 5aminopyrazoles (Scheme 18). Under thermal or microwave heating, these cyclocondensations led to fused pyridine or pyrimidine carboxylic acids. It was shown that refluxing on an oil bath of equimolar mixtures of 5-amino-3methylpyrazole (30) with unsaturated acids 3 in DMF or acetic acid allowed to obtain 4-aryl-3methylpyrazolo[3,4- $b]$ pyridine-6-carboxylic acids 33 (Scheme 18).

It should be noted that heterocyclic products in these reactions were not isolable as dihydroderivatives, which indicate the high propensity of the expected 4-aryl-3-methyl-4,7dihydropyrazolo[3,4-b]pyridine intermediates to oxidation.

Treatment of 5-amino-3-methyl-1phenylpyrazole (31) with arylidenepyruvic acids 3 in boiling DMF led to 4-aryl-3-methyl-1phenylpyrazolo[3,4-b]pyridine-6-carboxylic acids 34. However, the authors showed that refluxing the starting materials in boiling acetic acid allowed obtaining their dihydroanalogs $\mathbf{3 5}$, which were accompanied by only small amounts of heterocycles 34. Exposure of dihydropyridines 35 on air resulted in their oxidation to products 34 .

Refluxing arylidenepyruvic acids 3 with 5-amino-3-arylpyrazoles 32 allowed to isolate the mixtures of several regioisomers and products of their heteroaromatization $(\mathbf{3 6}, 37$ and $\mathbf{3 8})$ as the reaction was not regioselective in most cases.

It should also be noted that condensation of 5-aminopyrazoles 30-32 with the unsaturated acids 3 have never yielded isomers with opposite location of the aryl and carboxyl groups at the pyridine or pyrimidine rings. 


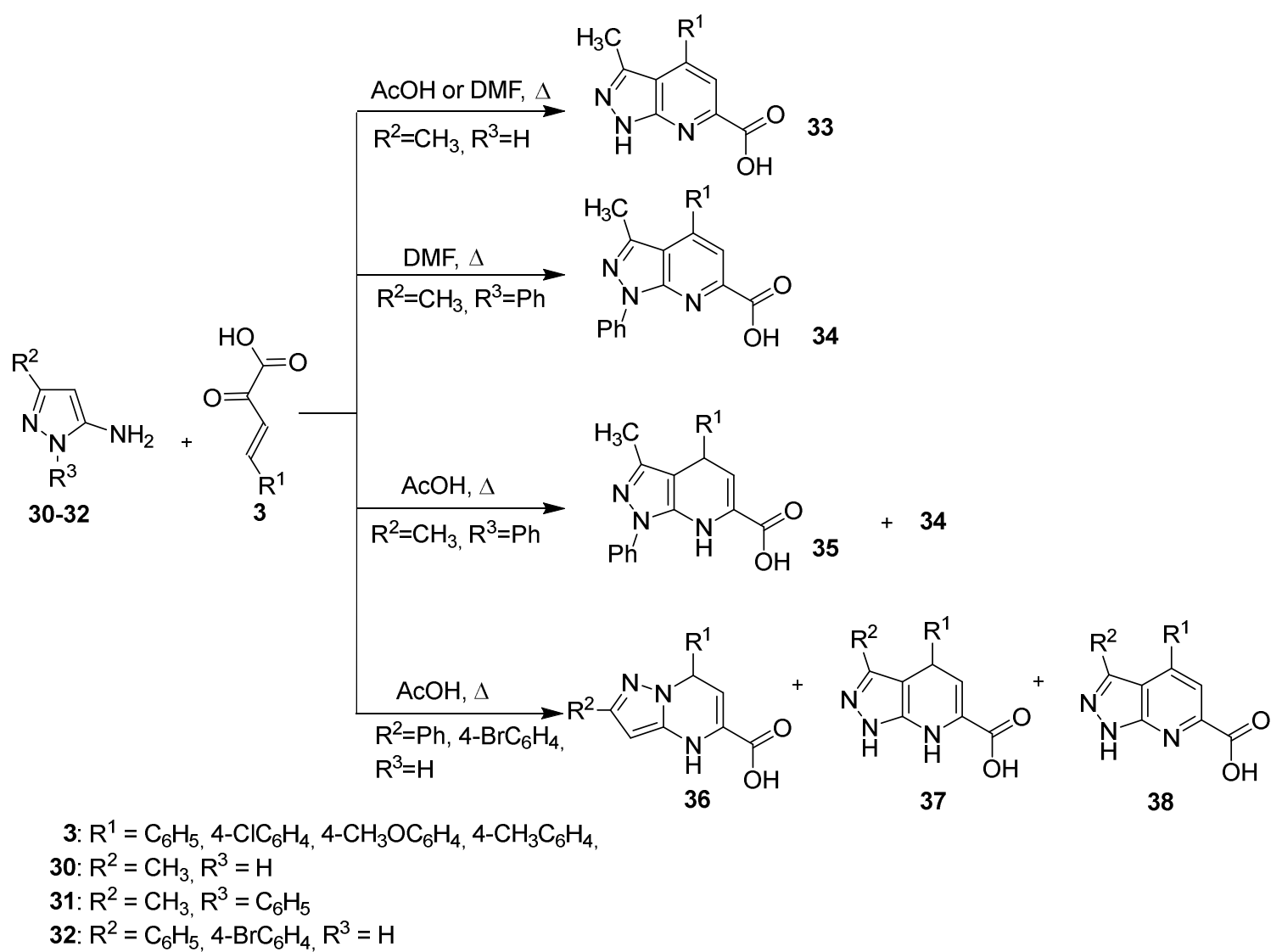

Scheme 18.

To solve the dilemma of obtaining the mixture of two regioisomers when 3-aryl-5aminopyrazoles $\mathbf{3 2}$ reacted with arylidenepyruvic acids 3 in boiling acetic acid the authors of the article [78] applied ultrasonication to this reaction (Scheme 19).

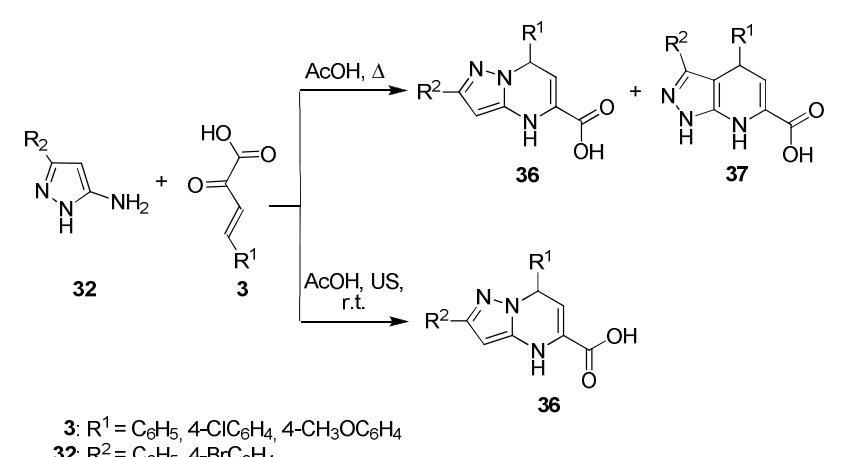

Scheme 19.

It was determined that cyclocondensation of the starting materials in acetic acid under ultrasonic irradiation at room temperature caused the formation of exclusively 2,7-diaryl4,7-dihydropyrazolo[1,5-a]pyrimidi-ne-5carboxylic acids 36 .

In the case of multicomponent reactions of pyrazoles 30-32 with pyruvic acid (1) and aromatic aldehydes 2 corresponding 6-aryl-3methylpyrazolo[3,4- $b]$ pyridine-4-carboxylic acids 39, 1,6-diaryl-3-methylpyrazolo[3,4b]pyridine-4-carboxylic acids $\mathbf{4 0}$ or 3,6diarylpyrazolo[3,4-b]pyridine-4-carboxylic acids 41 were formed (Scheme 20) [78].

It was a very surprising discovery that reactions of 3-substituted 5-aminopyrazoles 3032 with arylidenepyruvic acids $\mathbf{3}$ and the threecomponent cyclocondansation of the same pyra- 
zoles with pyruvic acids $\mathbf{1}$ and aldehydes $\mathbf{2}$ led to the formation of different reaction products, which differ in the location of the carboxylic and $\mathrm{R}^{1}$ substituents. It is also very important to mention that heteroaromatized compounds were formed as the result of the three-component reactions even under inert conditions.

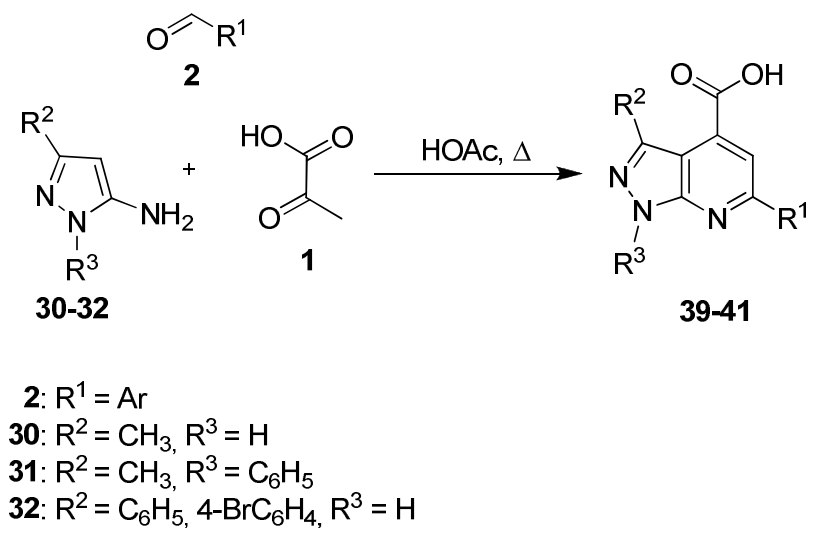

Scheme 20.

However, the treatment of 5aminopyrazoles with arylidenepyruvic acids not necessary leads to the formation of pyrazoloazines.

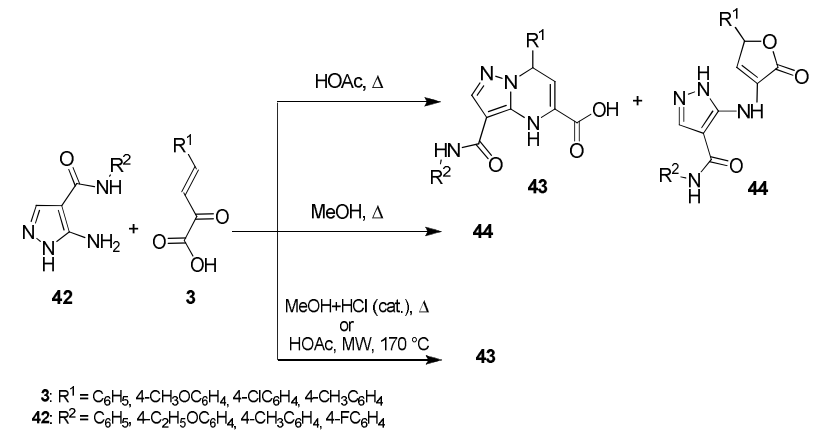

Scheme 21.

The authors of the article [80] showed that refluxing pyrazoles $\mathbf{4 2}$ with unsaturated acids $\mathbf{3}$ in acetic acid allowed to obtain the mixture of pyrazolopyrimidine-5-carboxylic acids 43 and pyrazolylaminofuranones 44 (Scheme 21) while heating the starting materials 3 and $\mathbf{4 2}$ in boiling methanol resulted in the formation of solely compounds 44 in high yields.

It is important to point out that the addition of catalytic amounts of $\mathrm{HCl}$ had a strong effect on this reaction. Thus, in contrast to the above observation where $\mathbf{4 4}$ was selectively obtained, addition of hydrochloric acid changed the direction towards compounds 43 . However, using $\mathrm{HCl}$ in methanol medium has a serious drawback: it causes the esterification of acids 43. To overcome this obstacle the authors [80] searched for the different reaction conditions and it was established that microwave irradiation $\left(2 \mathrm{~min}\right.$ at $\left.170^{\circ} \mathrm{C}\right)$ in acetic acid of the starting materials yielded only the acids $\mathbf{4 3}$.

The multicomponent reactions of pyrazoles 42 with pyruvic acid (1), and aldehydes 2 led to pyrimidines 43 (Scheme 22), which were identical to the compounds isolated as the products of the two-component cyclocondensations (Scheme 21).

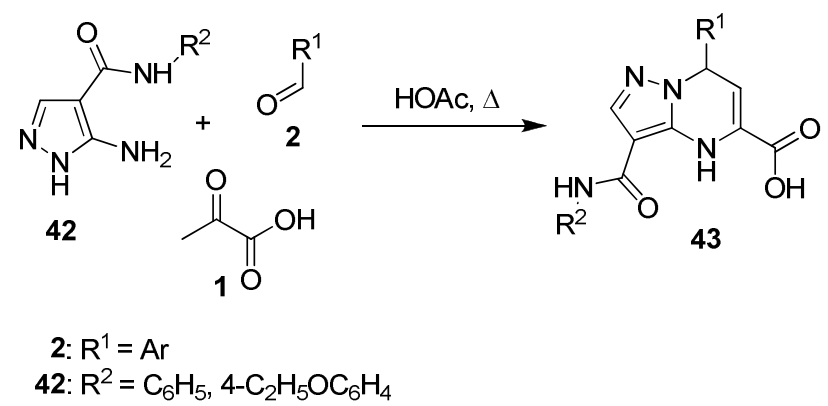

Scheme 22.

The interactions involving 3-amino-5methylisoxazole (45) with arylidenepyruvic acids 3 or their synthetic precursors, pyruvic acid (1) and aromatic aldehydes 2 , resulted in the 
formation of furanones $\mathbf{4 6}$ similar to compounds 44. At the same time heating $\left(80^{\circ} \mathrm{C}\right) 5$-amino-3methylisoxazole (47), arylidenepyruvic acids 3 in $\mathrm{AcOH}$ allowed to obtain only isoxazolopyridinecarboxylic acids 48 (Scheme 23) [81].

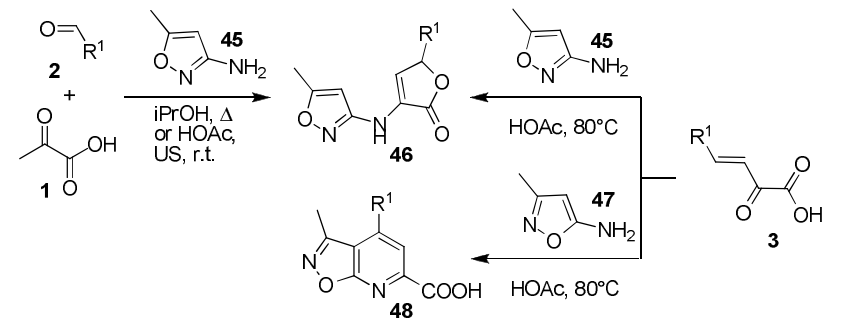

2, 3: $\mathrm{R}^{1}=\mathrm{C}_{6} \mathrm{H}_{5}, 4-\mathrm{CH}_{3} \mathrm{OC}_{6} \mathrm{H}_{4}, 4-\mathrm{ClC}_{6} \mathrm{H}_{4}, 4-\mathrm{CH}_{3} \mathrm{C}_{6} \mathrm{H}_{4}$

\section{Scheme 23.}

The influence of temperature regime on three-component reaction of pyrazole 42, phenylpyruvic acid (15), and aromatic aldehydes 2 was explored in publication [80]. Under ultrasonication of starting materials in acetic acid at room temperature tetrahydropyrazolopyrimidine-7-carboxylic acids 49 were only formed (Scheme 24).

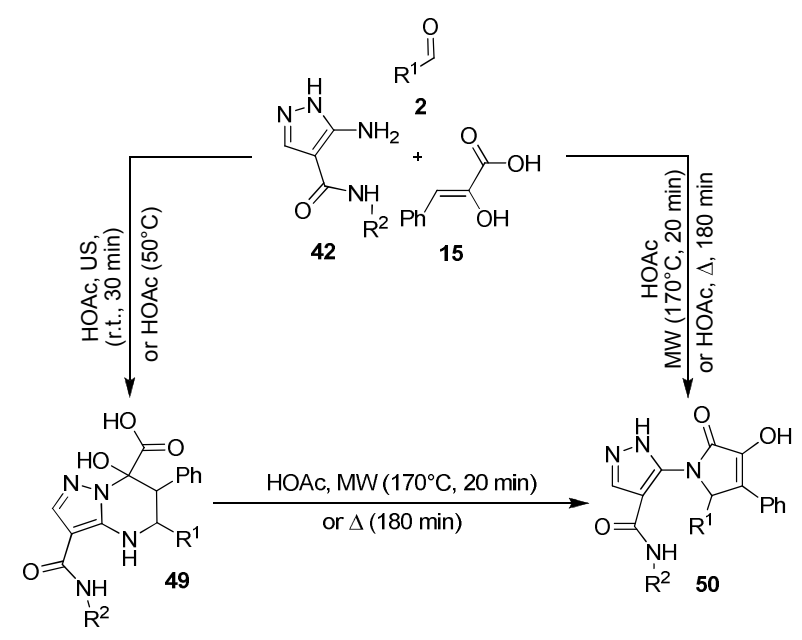

Scheme 24 .

On the other hand, refluxing pyrazole 42, phenylpyruvic acid (15), and aromatic alde- hydes 2 in acetic acid or their heating in the microwave reactor led to the formation of pyrrolones 50. The authors of articles $[80,81]$ concluded that compounds 49 were the kinetically controlled products, while compounds $\mathbf{5 0}$ were thermodynamically controlled ones.

Pyrrolones 51, similar to 50, were also obtained under refluxing 3-amino-5methylisoxazole (45) with aromatic aldehydes and arylpyruvic acid in HOAc, while the same three-component reaction involving isomeric 5amino-3-methylixazole (47) proceeded with the formation of the carboxylic acids 52 (Scheme 25) $[81]$.

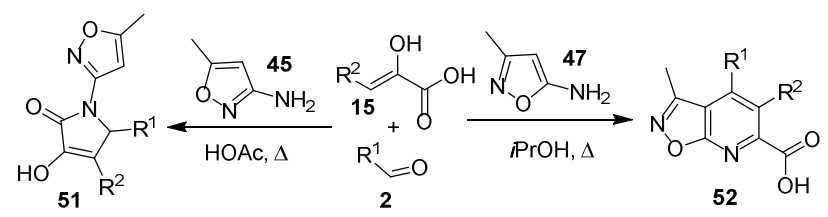

Scheme 25.

Some interesting results were found when 3-aryl-4-alkyl-5-aminopyrazoles 53 reacted with several esters of arylidenepyruvic acids 54 - the treatment yielded esters of 6-hydroxy2,7-diarylpyrazolo[1,5-a]pyrimidine-5carboxylic acids 55 (Scheme 26) [81]. In contrast, carrying out the same reaction under ultrasonication at room temperature caused the formation of the esters of 6-hydroxy-2,7diaryldihydropyrazolo[1,5-a]pyrimidine-5carboxylic acids 56 in mixtures with some amounts of compounds $\mathbf{5 5}$. It should be mentioned that further refluxing of compounds $\mathbf{5 6}$ in acetic acid allowed to obtain heterocycles $\mathbf{5 5}$; all 
the efforts to carry out the dehydration of esters 56 were in vain.

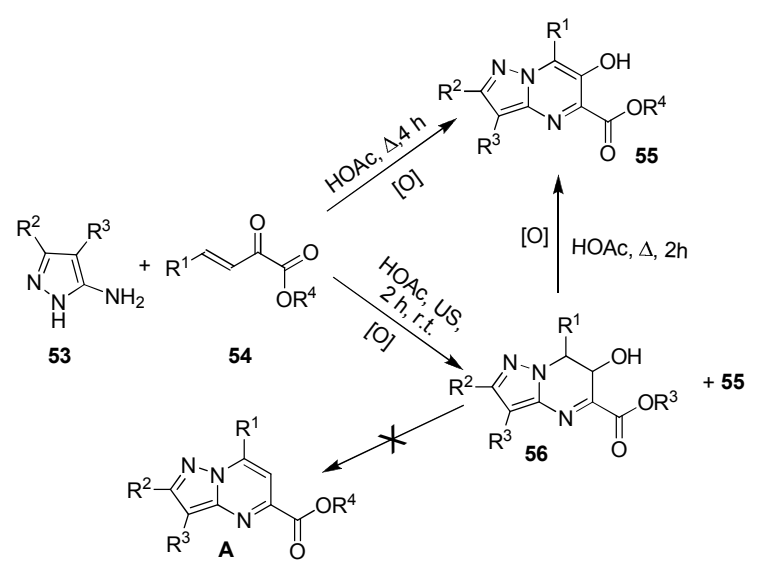

53: $\mathrm{R}^{2}=\mathrm{C}_{6} \mathrm{H}_{5}, 4-\mathrm{FC}_{6} \mathrm{H}_{4}, \mathrm{R}^{3}=\mathrm{C}_{2} \mathrm{H}_{5}$

54: $\mathrm{R}^{1}=4-\mathrm{CH}_{3} \mathrm{OC}_{6} \mathrm{H}_{4}, 4-\mathrm{ClC}_{6} \mathrm{H}_{4}, \mathrm{R}^{4}=\mathrm{C}_{2} \mathrm{H}_{5}, i-\mathrm{C}_{3} \mathrm{H}_{7}$

\section{Scheme 26.}

The multicomponent reactions of pyrazoles 53 with ethyl pyruvate (56) and aromatic aldehydes $\mathbf{2}$ in boiling acetic acid also led to pyrimidines 55 (Scheme 27) [81]. On the other hand, the same interaction under ultrasonication allowed obtaining 7-hydroxytetrahydropirazolopyrimidines 57.

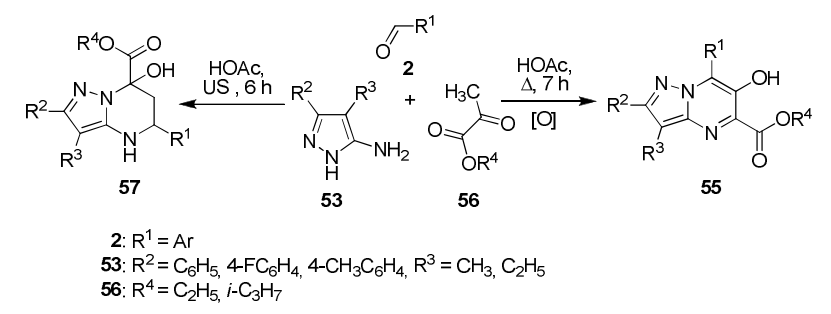

Scheme 27.

There were a lot of examples when the introduction of ortho-OH-group into aromatic ring of the aldehyde allowed the formation of several different chemotypes of final structures, i.e. oxygen-bridged [82-88], spiroheterocyclic compounds [89], lactones [85] and the other structures [82]. In continuation of the recent research $[44,45,52,58,78-80]$ dedicated to the tuning the selectivity of the reactions involving aminoazoles, aromatic aldehydes and pyruvic acids, the similar MCRs with the participation of ortho-hydroxybenzaldehydes were chosen as a challenging object for the study. It was found that variation of the temperature regime together with applying non-classical activation methods (ultrasonic and microwave irradiation) allowed to switch such reaction as well.

Thus, the condensation of pyruvic acid (1) with ortho-hydroxybenzaldehydes $\mathbf{1 0}$ and 5amino-3-arylpyrazoles $\mathbf{3 2}$ under conventional refluxing in acetic acid led to the pyrazolo[3,4b]pyridine-4-carboxylic acids 58 (Scheme 28) similar to those obtained in the reactions involving other aldehydes (Scheme 20) [90]. The substances 58 might also be obtained under microwave irradiation $\left(\mathrm{AcOH}, 150{ }^{\circ} \mathrm{C}, 20 \mathrm{~min}\right)$ that allowed a 4-fold reduction in the time of the process due to the higher reaction temperature [90].

However, the treatment of the same starting materials $\mathbf{1}, \mathbf{1 0}$ and $\mathbf{3 2}$ in acetic acid at room temperature with application of ultrasonic irradiation gave benzoxazocine-4-carboxylic acids 59 (Scheme 28). These oxygen-bridged heterocycles were stable upon boiling in a series of solvents (acetic acid, methanol, ethanol and butanol). However, their stirring in ethanol with addition of sodium hydroxide led to cleavage of the bridged fragment, oxidation and the formation of compounds $\mathbf{5 8}$ in $90 \%$ yields. MW irradiating compounds 59 in HOAc $\left(150{ }^{\circ} \mathrm{C}, 15\right.$ 
min) or heating them in DMSO for 48 hours also caused the formation of heteroaromatic carboxylic acids 58 (Scheme 28) [90].

The authors [90] considered azomethines as the intermediates of both heterocyclizations mentioned above. Indeed, treatment of the corresponding preliminary obtained imines with pyruvic acid led to the formation of compounds $\mathbf{5 8}$ and 59, respectively.

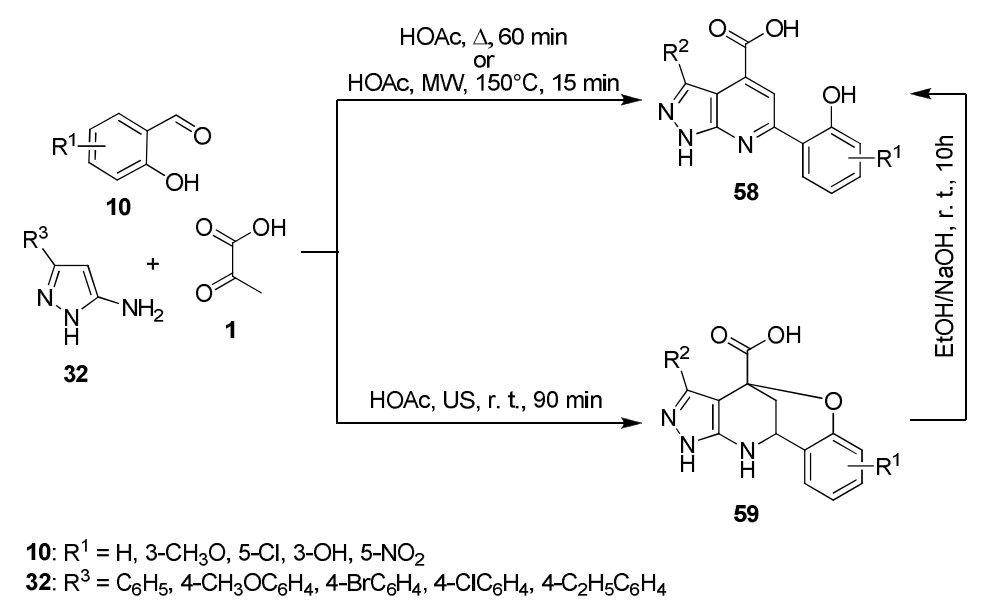

Scheme 28.

The possibility of the transformation of the azomethines into pyrazolopyridines like 58 by refluxing with pyruvic acid had been described in the earlier works [78].

As it was mentioned above, 5aminopyrazoles containing a substituent in the fourth position sometimes possessed specific properties and exhibited unusual behavior in multicomponent reactions [80, 91, 92].

However, it was found that heterocyclization of 5-amino-4-ethyl-3-(4fluorophenyl)pyrazole (53) and salicylaldehyde (10) both with pyruvic acid (1) and with arylpyruvic acids $\mathbf{1 5}$ in acetic acid under ultrasonication at room temperature led to the tetrahydroderivatives $\mathbf{6 0}$ similar to the reaction presented on Scheme 27 and no formation of bridged structures was observed (Scheme 29) [90].
Heterocyclization of pyrazoles $\mathbf{3 2}$ and salicylaldehyde (10) with arylpyruvic acids $\mathbf{1 5}$ under ultrasonic irradiation, in contrast to the multicomponent reactions involving pyruvic acid, proceeded with the formation of a pyrimidine ring instead of a pyridine one (carboxylic acids 61, Scheme 29).
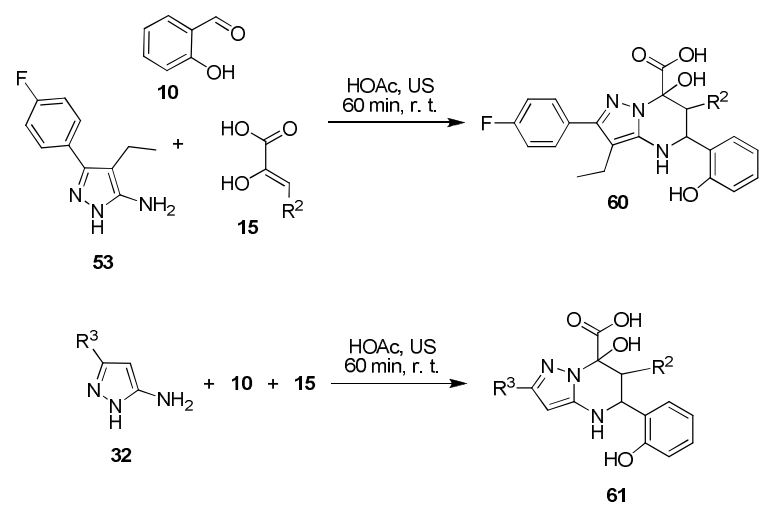

10: $\mathrm{R}^{1}=\mathrm{H}$

15: $\mathrm{R}^{2}=\mathrm{C}_{6} \mathrm{H}_{5}, 4-\mathrm{CH}_{3} \mathrm{OC}_{6} \mathrm{H}_{4}, 4-\mathrm{ClC}_{6} \mathrm{H}_{4}$ 32: $\mathrm{R}^{3}=\mathrm{C}_{6} \mathrm{H}_{5}, 4-\mathrm{ClC}_{6} \mathrm{H}_{4}, 4 \mathrm{C}_{2} \mathrm{H}_{5} \mathrm{C}_{6} \mathrm{H}_{4}$

\section{Scheme 29.}


Compounds 60 and 61 were also obtained in the reaction of the corresponding azomethines with arylpyruvic acids [90].

Antimicrobial activity of the heterocycles obtained was studied as well. For several of the compounds tested a sufficient increase in biomass of cultures compared with control was found [90].

\section{Conclusions}

Thus, the known literature data demonstrate high potential of linear and multicomponent heterocyclizations involving aminoazoles, aldehydes and pyruvic acids or its derivatives for organic synthesis and, in particular, for Diversity Oriented Synthesis. Switchable character of such reactions and possibility to tune their selectivity by variation of the reaction parameters opens the pathway to obtain diverse heterocyclic scaffolds from a limited set of starting materials.

\section{References}

[1] G.A. Epling, K.Y. Lin, J. Heterocycl. Chem. 1987, 24, 853.

[2] A. Saggiomo, K. Kato, T. Kaiya, J. Med. Chem. 1968, 11, 277.

[3] G. J. Atwell, B. C. Baguley, W. A. Denny, J. Med. Chem. 1989, 32, 396.

[4] D.J. Bhatt, G.C. Kamdar, A.R. Parikh, J. Indian Chem. Soc. 1984, 61, 816.

[5] J. Bergman, A. Brynolf, Tetrahedron 1990, 46, 1295.

[6] A.V. Milyutin, L.R. Amirova, V.E. Kolla, F.Ya. Nazmetdinov, L.P. Drovosekova, Yu.S.
Andreichikov, Khim.-Farm. Zh. 1998, 32, 24; (Pharm. Chem. J. 1998, 32, 422).

[7] H.Y. Aboul-Enein, S.E. Ibrahim, J. Fluorine Chem. 1992, 59, 233.

[8] A.V. Milyutin, R.R. Makhmudov, Yu.S. Andreichikov, A.F. Goleneva, G.A. Tul'bovich, T.I. Kovina, Khim.-Farm. Zh. 1996, 30, 20; (Pharm. Chem. J. 1996, 30, 374).

[9] O. Doebner, Ber. Dtsch. Chem. Ges. 1887, 20, 277.

[10] O. Doebner, Justus Liebigs Ann. Chem. 1887, 242, 290.

[11] W. Borsche, Chem. Ber. 1908, 41, 3884.

[12] W. Borsche, Ber. der Deutsch. Chem. Ges. 1910, 42, 4088.

[13] M. Toma, Gazz. Chim. Ital. 1952, 82, 40.

[14] J.R Johnson, R. Adams, J. Am. Chem. Soc. 1921, 43, 2255.

[15] O. Nitidandhaprabhas, Nature 1966, $212,5061$.

[16] H. Wasserman, R Koch, J. Org. Chem. 1962, 27, 35.

[17] R.B. Herbert, A.E. Kattah, E. Knagg, Tetrahedron 1990, 46, 7119.

[18] A. K. Mitra, A. De, N. Karchaudhuri, Synth. Commun. 1999, 29, 573.

[19] S.-J. Um, S.-H. Park, C.-H. Park, B.H. Chang, J.-H. Yoon, H.-S. Sin, Bull. Korean Chem. Soc. 2003, 24, 677.

[20] W.L. Meyer, W.R. Vaughan, J. Org. Chem. 1957, 22, 1560.

[21] W.R. Vaughan, L.R. Wyman, J. Org. Chem. 1953, 18, 389.

[22] B. Eftekhari-Sis, M. Zirak, Chem. Rev. 2015, 115 (1), 151.

[23] L.-M. Wang, L. Hu, H.-J. Chen, Y.Y. Sui, W. Shen, J. Fluorine Chem. 2009, 130, 406. 
[24] G. C. Muscia, J. P. Carnevale, M. Bollini, S. E. Asis, J. Heterocycl. Chem. 2008, 45, 611.

[25] S. Elhadi, Synthetic Commun. 2011, $41,1435$.

[26] C.M. McCloskey, J. Am. Chem. Soc. 1952, 74, 5922.

[27] H.G. Bhatt, Y.K. Agrawal, M. Patel, J. Med. Chem. Res. 2015, 24, 1662.

[28] T. Nixey, P. Tempest, C. Hulme, Tetrahedron Lett. 2002, 43, 1639.

[29] N. Vinot, P. Maitte, J. Heterocycl. Chem. 1982, 19, 349.

[30] I. Wiedermannova, J. Slouka, J. Heterocycl. Chem. 2001, 38, 1465.

[31] A. Colombo, J. Frigola, J. Pares, B. Andaluz, J. Heterocycl. Chem. 1989, 26, 949.

[32] B.S. Holla, B.K. Sarojini, B.S. Rao, B. Poojary, Indian J. Chem., Sect. B 2003, 42B, 2054.

[33] M.M. Abelman, S.C. Smith, D.R. James, Tetrahedron Lett. 2003, 44, 4559.

[34] W. Li, Y. Lam, J. Comb. Chem. 2005, 7, 721 .

[35] H.A. R. Hussein, Kh.M. Abu-Zeid, Egyptian J. Chem. 2007, 50, 6, 725.

[36] V.L. Rusinov, A.V. Myasnikov, T.L. Pilicheva, O.N. Chupakhin, E.A. Kiprianova, A.D. Garagulya, Khim.-Farm. Zh. 1990, 24, 39; (Pharm. Chem. J. 1990, 24, 52).

[37] S.M. Desenko, V.V. Lipson, N.I. Gorbenko, L.P. Pivovarevich, E.N. Ryndina, V.V. Moroz, V.P. Varavin, Khim.-Farm. Zh. 1995, 29, 37 ; (Pharm. Chem. J. 1995, 29, 265).

[38] W. Meng, R.P. Brigance, H.J. Chao, A. Fura, T. Harrity, J. Marcinkeviciene, S.P. O'Connor, J.K. Tamura, D. Xie, Y. Zhang et al, J. Med. Chem. 2010, 53, 15, 5620.

[39] V.L. Rusinov, T.L. Pilicheva, O.N. Chupakhin, G.V. Kovalev, E.P. Komina, Kh.-Farm. Zh. 1986, 20, 947; (Pharm. Chem. J. 1986, 20, 550).
[40] Z. Li-Yan, C. Chun, J. Comb. Chem.

2010, 12, 35 .

[41] Z. Li-Yan, R. Yi-Ming, C. Chun, Synthetic Commun. 2011, 41, 3635.

[42] M.A. El-borai, H.F. Rizk, M.F. AbdAal, I.Y. El-Deeb, Eur. J. Med. Chem. 2012, 48, 92.

[43] L.R.S. Dias, M.B. Santos, S. Albuquerque, H.C. Castro, A.M.T. de Souza, A.C.C. Freitas, M.A.V. DiVaio, L.M. Cabrale, C.R. Rodriguese, Bioorg. Med. Chem. 2007, 15, 211.

[44] V.A. Chebanov, S.M. Desenko, Ya.I. Sakhno, E.S. Panchenko, V.E. Saraev, V.I. Musatov, V.Ph. Konev, Physiologichno aktyvni rechovyny 2002, $1,33,10$.

[45] V.A. Chebanov, Ya.I. Sakhno, S.M. Desenko, S.V. Shishkina, V.I. Musatov, O.V. Shishkin, I.V. Knyazeva, Synthesis 2005, 15, 2597

[46] V.A. Chebanov, S.M. Desenko, Chem. Heterocycl. Comp. 2012, 48, 566.

[47] Yu.V. Sedash, N.Yu. Gorobets, V.A. Chebanov, I.S. Konovalova; O.V. Shishkin, S.M. Desenko, RSC Advances 2012, 2, 6719.

[48] V.A. Chebanov, K.A. Gura, S.M. Desenko, Top. Heterocycl. Chem. 2010, 23, 4.

[49] V.A. Chebanov, S.M. Desenko, T.W. Gurley, in Azaheterocycles Based on $\alpha, \beta$-Unsaturated Carbonyls, Springer, Meppel, 2008.

[50] V.A. Chebanov, S.M. Desenko, Diversity Oriented Synth. 2014, 1, 43.

[51] J. Zhu, Q. Wang, M.-X. Wang, in Multicomponent Reactions in Organic Synthesis, Wiley-VCH, 2014.

[52] Ya.I. Sakhno, S.M. Desenko, S.V. Shishkina, O.V. Shishkin, D.O. Sysoyev; U. Croth, C.O. Kappe, V.A. Chebanov, Tetrahedron 2008, 64, 11041.

[53] M.V. Murlykina, Ya.I. Sakhno, S.M. Desenko, S.V. Shishkina, O.V. Shishkin, D.O. Sysoiev, M.N. Kornet, D. Schols, Ja.L. Goeman, J.Van der 
Eycken, E.V. Van der Eycken, V.A. Chebanov, Eur. J.

Org. Chem. 2015, DOI: 10.1002/ejoc.201500469.

[54] W.R. Vaughan, I.S. Covey, J. Am. Chem. Soc. 1958, 80, 2197.

[55] J.R. Merchant, M.A. Hakim, K.S. Pillay, J.R. Patell, J. Med. Chem. 1971, 14, 1239.

[56] W.R. Vaughan, R.C. Tripp, J. Am. Chem. Soc. 1960, 82, 4370.

[57] W. Dieckmann, Chem. Ber. 1910, 43, 1024.

[58] A. Al-Najjar, K. Bowden, J., Chem. Soc., Perkin Trans. 2 1997, 993.

[59] V.M. Chernyshev, A.V. Astakhov, Z.A. Starikova, Tetrahedron 2010, 66, 3301.

[60] V.M. Chernyshev, V.A. Rakitov, V.A. Taranushich, V.V. Blinov, Chem. Heterocycl. Comp. 2005, 41, 1139.

[61] V.M. Chernyshev, A.E. Kosov, E.S. Gladkov, S.V. Shishkina, V.A. Taranushich, S.M. Desenko, O.V. Shishkin, Russ. Chem. Bull., Int. Ed. 2006, 55, 338.

[62] V.M. Chernyshev, V.A. Rakitov, V.A. Taranushich, Z.A. Starikova, Chem. Heterocycl. Comp. 2007, 43, 776.

[63] V.M. Chernyshev, V.A. Rakitov, V.V. Blinov, V.A. Taranushich, Z.A. Starikova, Chem. Heterocycl. Comp. 2009, 45, 436.

[64] P. Papini, Gazz. Chim. Ital. 1950, 80, 100.

[65] P. Papini, S. Checchi, Gazz. Chim. Ital. 1950, 80, 850 .

[66] P. Papini, Gazz. Chim. Ital. 1952, 82, 735.

[67] A. Bavley, US Patent 2406654 , 1946; Chem. Abstr. 1947, 41, 42h.

[68] Ya.I. Sakhno, S.M. Desenko, S.V. Shishkina, O.V. Shishkin, V.I. Musatov, V.A. Chebanov, Synthesis 2011, 1120.

[69] I. Tapia, V. Alcazar, J. R. Moran, M. Grande, Bull. Chem. Soc. Jpn. 1990, 63, 2408.
[70] N. Ghavtadze, R. Fröhlich, E. U. Würthwein, Eur. J. Org. Chem., 2008, 3656.

[71] M.I. Abasolo, C.H. Gaozza, B.M. Fernandez, J. Heterocycl. Chem. 1987, 24, 1771.

[72] K.C. Liu, B.J. Shih, C.H. Lee, J. Heterocycl. Chem. 1992, 29, 97.

[73] B. Groenendaal, E. Ruijter, R.V.A. Orru, Chem. Commun. 2008, 5474.

[74] F. Bossert, W.Vater, Med. Res.Rev. 1989, 9, 291.

[75] Y. Tsuda, T. Mishina, K.Araki,; J. Inui, T. Nakamura, Jpn. Patent 1986, 61, 227,584; Chem. Abstr.109, 120988.

[76] Y. Tsuda, T. Mishina, M. Obata, K. Araki, J. Inui, T. Nakamura, Eur. Pat. 1987, 19,870,408; Chem.Abstr. 106, 213976.

[77] K.S. Atwal, S. Moreland, Bioorg. Med. Chem. Lett. 1991, 1, 291.

[78] V.A. Chebanov, Ya.I. Sakhno, S.M. Desenko, V.N. Chernenko, V.I. Musatov, S.V. Shishkina, O.V. Shishkin, C.O. Kappe, Tetrahedron 2007, 63, 1229.

[79] V.A. Chebanov, Ya.I. Sakhno, S. M. Desenko, Ultrason. Sonochem. 2012, 19, 707.

[80] Ya.I. Sakhno, S.V. Shishkina, O. V. Shishkin, V.I. Musatov, E.V. Vashchenko, S.M. Desenko, V.A. Chebanov, Mol. Diversity 2010, 14, 523.

[81] V. Chebanov, A. Kozyryev, A. Morozova, E. Muravyova, M. Murlykina, Ya. Sakhno, Abstracts of the $8^{\text {th }}$ International Conference in Chemistry Toulouse-Kiev, 31 May - 4 June, 2015, Toulouse (France), p. P8

[82] N.Y. Gorobets, Y.V. Sedash, K.S. Ostras, O.V. Zaremba, S.V. Shishkina, V.N. Baumer, O.V. Shishkin, S.M. Kovalenko, S.M. Desenko, Erik V. Van der Eycken, Tetrahedron Lett. 2010, 51, 2095.

[83] W.S. El-Hamouly, A-M.A. ElKhamry, E.M.H. Abbas, Ind. J. Chem. 2006, 45B, 2091. 
[84] J. Svetlik, V. Hanus, J. Bella, J. Chem. Res. Synop. 1991, 1, 101.

[85] J. Svetlik, L. Veizerová, Th.U. Mayer, M. Catarinella, Bioorg. And Med. Chem. Lett. 2010, 20, 4073 .

[86] J. Svetlik, L. Veizerová, V. Kettmann, Tetrahedron Lett. 2008, 49, 3520.

[87] J. Svetlik, L. Veizerová, Helv. Chimica Acta 2011, 94, 199.

[88] J. Svetlik, F. Tureček, V. Hanuš, J. Chem. Soc., Perkin Trans.1. 1988, 1, 2053.

[89] J. Svetlik, V. Kettmann, Tetrahedron Lett. 2011, 52, 1062.

[90] M.V. Murlykina, Ya.I. Sakhno, S.M. Desenko, I.S. Konovalova, O.V. Shishkin, D.A. Sysoyev, M.N. Kornet, V.A. Chebanov, Tetrahedron 2013, 69, 9261 .

[91] V.A. Chebanov, V.E. Saraev, S.V. Shishkina, O.V. Shishkin, V.I. Musatov, S.M. Desenko, Eur. J. Org. Chem. 2012, 5515.

[92] E.A. Muravyova, S.M. Desenko, R.V. Rudenko, S.V. Shishkina, O.V. Shishkin, Y.V. Sen'ko, E.V. Vashchenko, V.A. Chebanov, Tetrahedron 2011, 67, 48, 9389. 